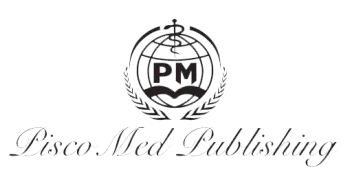

\title{
Original Research Article \\ Thinking on the Reform of Law Education Based on Practical Teaching Method
}

\author{
WuHan luan* \\ Baicheng Teachers College, Baicheng, Jilin 137000, China.
}

\begin{abstract}
At present, China's legal system is gradually maturing. In the process of educational development, legal education is beginning to be incorporated into key education. But at present, there is a relatively single legal education model in China, the main goal of students' study is to study the theory of law and the basic legal content, which can not cultivate students' legal consciousness and practical ability, and is not conducive to the comprehensive development of students. Therefore, we need to pay attention to the reform of legal education, through the new form of teaching measures to constantly update the concept of education, in order to improve the quality of teaching.
\end{abstract}

Keywords: Law Education; Thoughts on Reform; Practical Teaching Method

\section{Introduction}

The law education only attaches great importance to the students to learn theoretical knowledge under the traditional concept, but it does not effectively cultivate students' practical ability. The law major is a course with a strong theoretical and practical nature. Relying only on the principles of law will lead to the one-sided development of learning. We should not only allow students to fully master theoretical knowledge, but also cultivate their legal professional skills, so as to effectively combine practice and theory. Through legal knowledge, students can improve their legal professional skills and combine them with practice to consolidate legal theory, thereby enhancing their comprehensive legal literacy.

\section{Educational idea and teaching method of innovative law}

Our country attaches great importance to law courses, but it has not paid attention to cultivating students' practical ability, and it has not fully considered social needs, which leads to the inability to implement practical teaching and abandons important contents of law education in the classroom. First of all, the law courses are mainly based on the legal provisions issued by our country as the standard. There are few courses, which cultivate students' practical ability. Generally speaking, the law courses mainly teach legal knowledge, which does not conform to the educational model after the integration of theory and profession ${ }^{[1]}$. Secondly, in the process of legal education, teachers will focus on explaining the basic theories and relevant legal provisions for students. The teaching goal is to guide students to fully grasp the system knowledge system, and then analyze the provisions based on legal knowledge to find the causes of problems. However, the analysis of provisions in daily life needs to be consistent with conflicts of interest, ascertaining facts and handling interpersonal relationships. Third, at this stage, my country's law curriculum will involve a wider range, but the proportion of international commercial law and market economy in the curriculum is not high. We need to improve the curriculum based on these contents. Under the influence of historical factors, our country pays more attention to setting up history courses in legal education, ignoring the application departments in law courses. The economic law established at this stage is based on economic planning, so that the standards of the economic market are difficult to meet. When studying civil and commercial law in the classroom, it only discusses legal theories and clauses. It does not train students' practical ability.

\section{Problems in law education}

\subsection{Problems in classroom teaching}

At present, the current situation of classroom teaching is still not clear in legal education, and the trend of formalized legal education has caused a direct impact. For example, in a mock court situation in the classroom, students will recite words on the spot during practice, and students are in a weak state of performance. In view of the current situation, we can understand that the reality

Copyright (C) 2020 WuHan luan

doi: 10.18282/1-e.v9i4.1674

This is an open-access article distributed under the terms of the Creative Commons Attribution Non-Commercial License (http://creativecommons.org/licenses/by-nc/4.0/), which permits unrestricted non-commercial use, distribution, and reproduction in any medium, provided the original work is properly cited. 
of the simulated trial scene is not sufficient, which will reduce students' interest in learning and make students unwilling to learn legal knowledge. Not only that, it will also cause the goal of legal practice education to fall short of the ideal standard, prompting students to still only learn textbook knowledge during the learning process, but also to remember the content in the textbook. The reason for this state is that the practical operation training is not Perfect, unclear legal professional knowledge makes it impossible to continue classroom teaching and is seriously out of touch with real life ${ }^{[2]}$. Not only that, but some teachers and law students have not paid much attention to practical legal education courses.

\subsection{The problems of law teaching under the influence of conditions}

During the period of legal education, there were so many influencing factors that we could not guarantee the quality of teaching. The first was the lack of sufficient teaching staff. Many teachers did not have legal professional resumes and had weak practical guidance capabilities, which prompted the standard is difficult to reach. Secondly, there is a lack of practical venues for law teaching, and it is impossible to integrate quality education and practical teaching. For example, when training the professional quality of law students, such quality education can play a key role for students to study professional courses. There are no courses related to eloquence training in law teaching, so that it is difficult to ensure that students study law well.

\section{Ensuring the quality of practical law teaching}

\subsection{Strengthening the practical teaching of law education}

The goal of legal education is not only to impart legal knowledge, but more importantly, to strengthen the training of relevant personnel engaged in the legal profession. At present, the status quo of legal education is that there is a situation of neglecting practical teaching and paying too much attention to achievement. This has prompted many law students to use legal means to solve the problems in their lives after leaving school. They can only recite legal provisions. At present, law students in our country can only obtain the qualification to engage in the judicial profession after passing the professional judicial examination. After graduating from law students, the first thing they face is various judicial examinations. Due to the low efficiency of the examination items, many fresh graduates cannot engage in legal professions. In response to this situation, when carrying out legal education, it is necessary to consider the needs of the society, in accordance with the standards of social requirements, to cultivate students' comprehensive ability, and to strengthen students' legal practice. Not only that, but law teachers also need to have good working experience in the legal profession. They need to constantly update legal teaching concepts, improve teaching strategies, prevent the disconnection between theory and practice, and fully realize the importance of legal education to students. It is necessary to continuously explore educational forms, reform teaching methods, and further improve teaching quality.

\subsection{Enhancing the teaching effect of practical law}

To create practical teaching based on legal teaching, teachers should ensure the practicality of the courses when conducting legal classes. In the course, through the mock court scene and the actual operation of the lawyer, students can put themselves in a legal environment. For the legal problems that arise, the legal provisions can be reasonably used for targeted solutions, so that students can improve their ability to practically use legal knowledge. For example, in a mock court trial, students can be allowed to play roles with different identities, including lawyers and presiding judges. Students can improve the authenticity of the mock court, allowing students to experience the trial in the classroom, imitate the trial process, strengthen students' legal level, and achieve practical legal teaching purposes.

\subsection{Practice teaching in different forms of law teaching model}

Based on the concept of the new era, the traditional form of legal education is too single and gradually replaced by modern legal education models. The key to legal education is to change the traditional learning mode of students. Teachers act as students' guides and organizers in this process. We should focus on cultivating students' comprehensive abilities. When carrying out law classes, constantly innovate teaching models, exercise students' thinking ability, introduce new teaching models into classroom teaching, and mobilize students' enthusiasm through good teaching concepts and strengthen students' practical ability. The focus of the law teaching reform is to change the original learning philosophy of students. Teachers should pay attention to interesting classroom teaching to make students willing to learn legal knowledge. Teachers can use the form of grouping in classroom teaching to allow students to discuss and analyze legal knowledge, so that students can memorize legal provisions in the learning process, and use the discussion results reasonably in actual cases and analyze the cases logically. Students can also have cross-discussions, through good communication, mutual influence and common progress.

\section{Enable students to engage with real cases as clients}

When conducting law classes, if you want to ensure the good application of practical teaching, it is not enough to rely on simple answers. It is also necessary to clarify the verification method, change the traditional education concept, and cultivate students' independent thinking ability through a good education model. In practical law teaching, students can be allowed to contact them as parties to real cases. Based on the current situation, students can enhance their sense of responsibility, make them willing to take charge of the case, and find ways to protect their rights and interests from the perspective of the parties. In order to improve the practical operation ability of law students, teachers should urge students to participate more in the trial of practical cases in the law class, so that students can strengthen their own learning motivation in the process of practice and be willing to learn legal knowledge independently. By looking for verification methods and finding the final answer, students can feel the joy of personal experience in the learning process, and use their knowledge reasonably in real life, effectively improving students' legal level and ensuring the quality of law teaching. 
Original Research Article

\title{
Research on Social Development and Management Based on Social Network Analysis
}

\author{
Chenchen Ma* \\ Xi'an Jiaotong University, Xi'an, Shaanxi 710049, China.
}

\begin{abstract}
If you want to understand the social development and management of social network analysis, you must first know what social network analysis is. The network not only refers to the things that we usually use to surf the Internet, make calls, chat, etc., it is actually a relationship structure, a medium that links all aspects of related or unrelated things, and social network refers to the social The medium that connects various relationships is mainly to connect the individual with the social system. Everyone has his own way of behavior, has his own role in society, plays his own role, and effectively connects these individuals, just like our interpersonal communication in society, forming a social network. The Internet is actually the interaction of people in the social environment. It is similar to the Internet that we usually come into contact with. It has both restraints and development.

Keywords: Social Network; Social Development Management; Actors; Knowledge Management; Social Resource Allocation

\section{The essence of social network analysis}

Social network analysis consists of the following two main elements. The first is the actor. The so-called actor generally refers to the individual, but it is not limited to the individual. People and groups with active creativity can be an actor, like an actor. A work team, a company, an individual merchant, as long as he or they create something valuable in the same direction, can be called an actor, and the actor is like a point on a chessboard in the social network. It is the basis on which all relationships can proceed. Only with these nodes can there be subsequent connections. Speaking of connection, the second element of social networks is the relationship bond, which refers to the various connections between actors ${ }^{[1]}$. There are various relationships between people. For groups, the common relationships include cooperation, competition, confrontation, exchange, etc., and further personal relationships are more complicated, such as relatives, friends, classmates, colleagues, etc. It is the relationship bond we usually come into contact with. It also proves that each of us cannot exist alone without others.
\end{abstract}

\section{What is the composition of social networks}

We understand the main elements of social network, and then look at the form of social network, the most common of which is the group of two people, but also the most simple and basic form of social network, that is, the connection between two people, although simple, but it is the basis for the analysis of social relations, cannot be ignored. There are two groups of naturally there are three groups, it is similar to groups of two people, is composed of three people, but more than one person, has been able to make simple social relations into a small social network. Any form of human relationship can form a collection, that is, a small network, we also call sub-groups, simply speaking, small groups of society, similar to the community in schools, are a special relationship can make people connected to small groups. But we are in a group is not a single, can be a person in a lot of sub-groups, after all,

Copyright (C) 2020 Chenchen Ma

doi: 10.18282/1-e.v9i4.1675

This is an open-access article distributed under the terms of the Creative Commons Attribution Non-Commercial License (http://creativecommons.org/licenses/by-nc/4.0/), which permits unrestricted non-commercial use, distribution, and reproduction in any medium, provided the original work is properly cited.

\section{Conclusion}

As long as we reasonably carry out practical legal teaching, we can effectively exercise students' practical ability and enhance students' comprehensive ability. Therefore, when reforming legal education in our country, we should pay attention to perfecting practical legal teaching and fundamentally resolve the contradiction of students' legal knowledge.

\section{References}

[1]Yang Jiaorao. Practical legal teaching and legal education reform [J]. Legal System and Society, 2019; (17):203-204. [2]Xie Hui. Practice Skills Training Model of Law Education Based on Mobile Internet Environment [J]. Journal of Inner Mongolia Radio and TV University, 2019; (1):109-113. 